\title{
Economy-wide sources of agricultural expansion in developing countries
}

\section{Ian Coxhead}

Department of Agricultural and Applied Economics, University of Wisconsin, Wisconsin, USA

E-mail: coxhead@facstaff.wisc.edu

\section{Douglas Southgate}

Department of Agricultural, Environmental and Development Economics, Ohio State University, Ohio, USA

E-mail: southgate.1@osu.edu

\begin{abstract}
Due to the past parochialism of environmental economists and development specialists alike, environmental problems in developing countries were long neglected. There is substantial agreement on the causes of one such problem - forest loss - in countries caught in a low-level poverty trap. Less well understood are the reasons why agricultural encroachment on natural habitats does not often abate very much once development commences. Recent experience in Thailand indicates that deforestation in the face of rising living standards has to do with changing demands for agricultural output and the agroclimatic advantages of frontier areas, among other factors. More than anything else, reconciling environmental concerns with rural income growth depends on the growth of off-farm employment.
\end{abstract}

Keywords: agricultural colonization; development and the environment; tropical deforestation.

Reference to this paper should be made as follows: Coxhead, I. and Southgate, D. (2000) 'Economy-wide sources of agricultural expansion in developing countries', Int. J. Agricultural Resources, Governance and Ecology, Vol. 1, No. 1, pp. 68-76.

\section{Introduction}

At least as much as in any other scholarly field, environmental economics reflects prevailing conditions and concerns in the setting where it originated, in this case North America, Europe, and other wealthy parts of the world. Obviously, much of the literature dealing with natural resource allocation issues focuses on environmental values that the poor regard with casual interest at most, but that grow in importance as living standards rise. Among these values are willingness to pay for the preservation of natural habitats that yield little in the way of tangible output. 
Moreover, the backdrop for the great bulk of economic analysis of environmental problems corresponds to what one finds in places inhabited by the well-off. Beyond discussions of misallocation caused by one kind of spillover or another or perhaps a lack of competition, it is usually taken for granted that markets function reasonably well. This is because, in rich countries, the inefficiencies resulting from unwarranted regulation by the state are widely recognized, and are therefore generally avoided. At the same time, the institutional antecedents for market exchange, such as formal and informal mechanisms for the enforcement of contracts and property rights, are in place. By contrast, the governments of many poor countries have been enthusiastic about meddling with market forces while neglecting the institutional development required for a robust market economy.

There is another feature of the affluent backdrop for economic analysis of natural resource issues. When the question of substitution between natural resources and other kinds of productive wealth is raised, as it is in the literature addressing the topic of sustainability, the consequences of chronic and extreme shortages of non-environmental assets human capital, for instance - are rarely considered. Such shortages, of course, do not normally occur in places that enjoy elevated standards of living.

That environmental economists have had a parochial outlook in years past is demonstrated by the absence of nontrivial references to development in the original two volumes of North-Holland's authoritative Handbook of Natural Resource and Energy Economics [1]. But past neglect of environmental problems in poor countries also had much to do with omissions by development specialists. As prominent economists report, the index to the first two volumes of the North-Holland Handbook of Development Economics [2] contains no references at all to resource depletion or degradation or to environmental topics [3]. Environmental issues first received direct attention only with the publication of a third volume, in 1995.

Sub-disciplinary boundaries began to be breached during the late 1980s, when environmentally sustainable economic development first attracted substantial attention. Insights from the development field turn out to be indispensable when one tries to come to grips with the resource depletion and environmental damage occurring in economies that are mired in or emerging from poverty. At the same time, what environmental economists have to say about market failure and its correction greatly enriches any discussion of changes in the use and management of natural resources that coincide with economic progress.

Certainly, thorough analysis of tropical deforestation and its causes draws heavily on both fields.

\section{Deforestation, poverty and development}

It is abundantly clear that spillover impacts of global proportions result when tree-covered land near the Equator is cleared so that an expansion of alternative - mainly agricultural - land uses can be accommodated. Tropical forests harbour much of the world's flora and fauna. In addition, destruction of natural habitats contributes to increased concentrations of $\mathrm{CO}_{2}$ and other greenhouse gases. However, biodiversity loss and global warming are of little consequence where just about everyone is poor. Accordingly, deforestation in the midst of poverty is best interpreted not as a market failure but rather as the outcome of coping strategies that difficult circumstances oblige individual households to adopt. 
The failure to sustain real increases in aggregate income in excess of population growth results in low rates of new job creation outside of agriculture and other natural resource-based sectors as well as declining labour productivity throughout the entire economy. The lack of accumulation of physical capital that creates this situation is typically matched by inadequate support for education. Together, both kinds of under-investment create a 'low-level' trap into which many countries, most notably in Sub-Saharan Africa, have fallen at times.

Populations caught in the trap must turn to the natural resource base to find productive factors with which unskilled labour can be matched in order to produce either subsistence or income. Open-access land at the agricultural frontier the forest margin, in many cases - presents the easiest or even the only opportunity. Relatively stable forest, bushfallow, or pastoral systems are converted to more intensive uses, especially the production of short-season food crops for humans and livestock. Of course, this change is facilitated where investment in the institutions that undergird the marketplace has been as meagre as the accumulation of human and physical capital has been. In particular, tree-covered land is treated as an open-access resource, ripe for colonization, where property rights are poorly articulated and enforced.

In places that have experienced little economic progress, low living standards and the geographic expansion of impoverished agriculture are both symptoms of development failure - a development failure related to the inadequate formation of human skills, machinery, institutions and other non-environmental wealth. There is substantial agreement on this point.

Less well understood is the deforestation that takes place in countries experiencing rapid development. All agree that an intrinsic feature of sustained growth in per capita income is the relative decline of agriculture, as manifested by the sector's falling relative contribution to national income, the diminished ratio of farm employment to total employment and decreases in food expenditures as a share of total consumption. In light of the structural transformation that occurs as development takes place, it is ironic and somewhat puzzling that encroachment on forests, soil depletion, and related environmental ills are seldom observed to diminish significantly even in economies experiencing many years of growth. Apparently, simply alleviating poverty is not a sufficient condition for a switch to more sustainable patterns of land use.

Although incentives in economies that have escaped or avoided the low-level poverty trap are in many ways different from incentives in those that have not done so, resource use outcomes, including the colonization of land at agriculture's extensive margin, are often quite similar. Rapid economic growth, the opening to trade, and associated changes in the structure of production and patterns of consumption create new markets, or markets for new goods. As a result, farmers, migrants, and others along the agricultural frontier are encouraged to engage in the commercial production of plantation or vegetable crops, intensive livestock operations, large-scale pulse/grain cultivation, or commercial forestry. In some cases, movement to the extensive margin is driven by agroclimatic factors. In tropical countries, for example, temperate-zone vegetables must be grown at higher elevations.

Regional, national, and international market forces often shift dramatically as development proceeds, quite often in ways that increase the pressure on agriculture's extensive margins. By contrast, property institutions are usually slow to change. Consequently, occupying open-access land continues to be an option, as it is where there has been little economic progress. Furthermore, the frontier's appeal has to do with the free disposal of pollutants. There are no 
penalties for pesticide drift, for example. Neither are there any private consequences for the leaching of chemicals and animal wastes into waterways. In short, uncorrected externalities become a problem - one that is frequently exacerbated when distortionary price and trade policies encourage the waste and misallocation of environmental resources.

To be sure, conventional indicators of economic growth grow progressively more misleading as market and policy failures and the inefficiencies they induce multiply. Also, the gains from economic progress are seldom distributed evenly. Consequently, the resource degradation characteristic of the low-level poverty trap often coincides with the environmental damage resulting from development, even in small geographic areas.

Finally, it is by no means impossible in a developing economy for large segments of the population to slide back into poverty, during extended drought for example, or following a negative shock to the economy's terms of trade. Accordingly, fluctuations in economic growth and the distribution of its gains can lead to alternating regimes in which resource degradation is driven first by poverty, then by growth, and then by poverty again. Such a cycle was played out in various parts of the developing world before and during the debt crisis of the 1980s. It has emerged again in southeast Asia because of recent economic dislocations.

\section{Development, poverty alleviation and the environment in Thailand}

To summarize, growth and poverty alleviation are clearly the most important factors conditioning agricultural land use and agriculturally-related deforestation. However, specific resource use patterns can be traced to a range of policies (and policy failures) and reforms occurring in economies experiencing a rise in living standards. In addition, the operation of markets, especially those for labour, credit and agricultural products, plays a major role in determining how and in what form growth and other macroeconomic changes reach natural resource users. The developing economies of south-east Asia provide a fascinating laboratory for the formulation and testing of hypotheses in this field, both because those economies have accomplished an astonishingly rapid rise out of poverty and also because a diverse array of policies has been applied in the region.

Thailand's expansion between 1986 and 1995, for example, reveals much about linkages between growth and poverty alleviation on the one hand, and resource use along agriculture's extensive margin on the other. During those ten years, real per capita income boomed, increasing by more than four percent per annum. However, the gains of development were not distributed uniformly among various sectors (Table 1). Agriculture - historically the mainstay of the economy, the primary employer and the major source of export earnings - captured only a small part of new investment. As the most labour-intensive sector, it found itself less able to compete as the rapid expansion of labour demand in other sectors pulled up wages. The boom in labour-intensive manufacturing as well as in services (e.g. construction) thus accelerated agriculture's relative decline. From 1989 to 1995 nearly three million workers out of a total agricultural labour force of about twenty million walked off the land (Figure 1). As a result, planted area, which had increased steadily since the 1960s, stagnated and even began to fall (Figure 2). 


$$
\text { | }
$$

Economy-wide sources of agricultural expansion in developing countries

5

Table 1 Aggregate and agricultural output growth rates (percent per year). Source: World Bank data reported in Coxhead and Jiraporn [4]

\begin{tabular}{lllll}
\hline Period & GDP & Agriculture & Difference & $\begin{array}{l}\text { Agr growth as \% of } \\
\text { GDP growth }\end{array}$ \\
\hline $1965-80$ & 7.2 & 4.6 & 2.6 & 64 \\
$1980-90$ & 7.6 & 4.0 & 3.6 & 53 \\
$1990-94$ & 8.2 & 3.1 & 5.1 & 38 \\
\hline
\end{tabular}

Figure 1 Agricultural labour (in millions) by region, 1961-1995. (1 rai = 0.16ha)

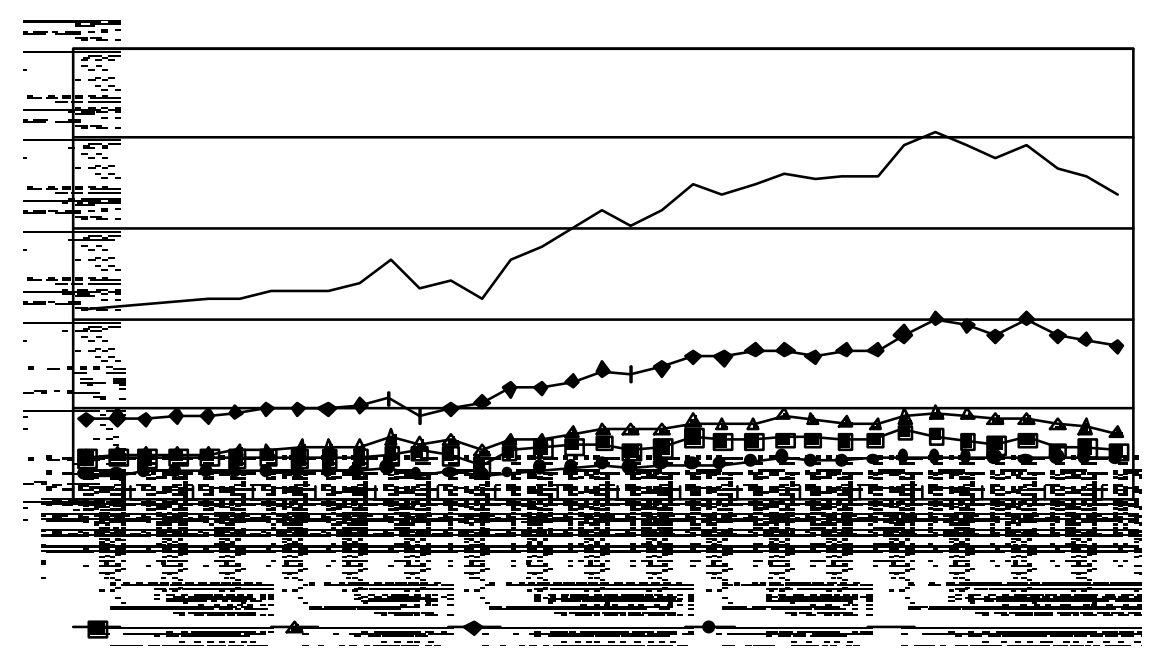


Figure 2 Agriculture-planted area (rais, in millions) by region, 1961-1995.

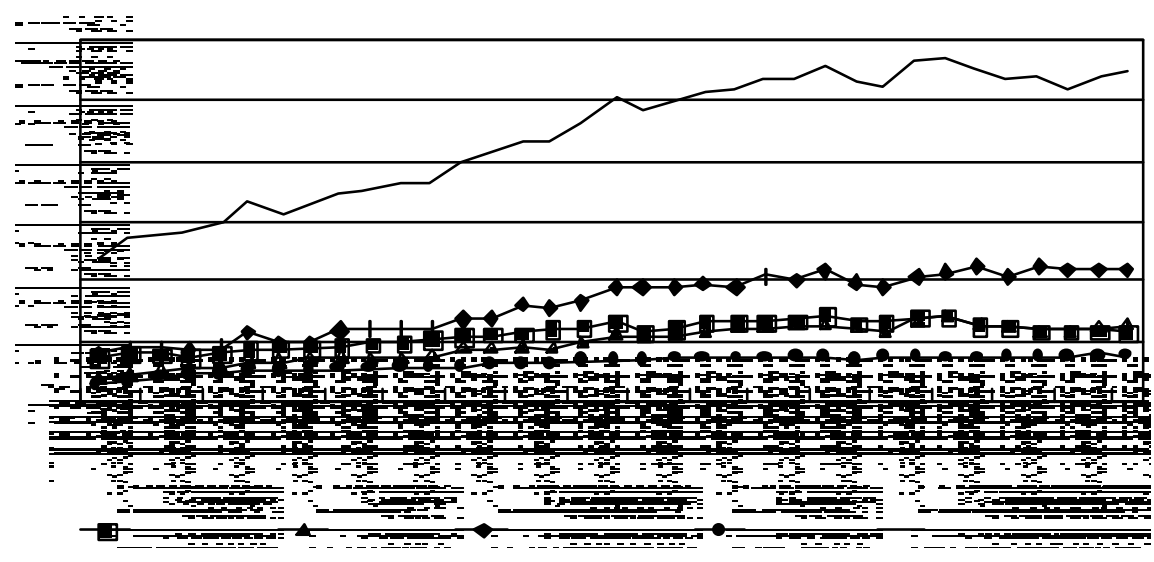

Certainly, many parts of the farm economy have continued to expand, thereby arresting agriculture's geographic contraction. During the 1970s, Thailand became a major exporter of cassava to Europe, a change in trade patterns that initiated a trend toward large-scale production of field crops in upland areas. In an era of rapidly rising wages, this trend was reinforced by diminished labour costs, made possible by rapid mechanization and the wider use of herbicides for weed control. In addition, policy shifts, including infrastructure provision, direct subsidies, as well as the indirect advantages conferred by trade liberalization in other sectors, have worked to the benefit of farmers specializing in corn, soybeans, and other field crops.

It is particularly surprising that the geographic contraction of farming during the 1980s and 1990s has not been proportionately larger in far-flung provinces where soils do not lend themselves very well to crop production - in upland areas, to be specific. On the contrary, market forces unleashed by development have induced a revolution in farming in the frontier (or former frontier) areas of northern Thailand. Instead of declining, agricultural land use in that region has actually increased.

Just two decades ago, upland agriculture in a typical northern province like Chiang Rai or Chiang Mai consisted mainly of the raising of food crops primarily for subsistence. For more than three-quarters of farm families, animaldrawn carts were the only means of transport over roads that were frequently impassable during the rainy season. More than 90 percent of the rural population derived income exclusively or primarily from crop production. Poverty was endemic and average educational attainment was extremely low.

Today, the region's rural population earns a large fraction of its income from seasonal or permanent participation in non-farm and urban labour markets. There has been an extraordinary demographic transition in which the average number of children per rural family has fallen by approximately a half in a single generation. For the typical household, all these changes have dramatically raised real income and reduced the variability of earnings across seasons and years. 
Econometric analysis of changes in agricultural land use at the provincial level suggests that off-farm employment is, indeed, an important causal factor. In regressions that use measures of infrastructure, land quality, upland area, and education (a proxy for labour mobility) to explain agricultural land use decline, the last variable is found to carry the greatest explanatory power [4]. Within uplands, the greatest declines in planted area have occurred where labour is most mobile. Throughout south-east Asia, the clear implication is that land retirement and other changes that diminish pressure on upland soils and forest resources will be more likely to occur in countries and regions where rates of nonagricultural employment creation are high and where farmers and their children are capable of moving to other jobs.

That upland agriculture has still expanded geographically in spite of higher and more diversified incomes, reduced food security concerns and, above all, a decline in the agricultural labour force, is explained by the transition from subsistence to commercial farming. Taking advantage of the proliferation of paved roads, pick-up trucks, and even cellular telephones, households whose farm production was once limited to staples are now able to raise a much wider range of crops for sale to processors and in distant urban markets. Within Thailand, temperate-climate crops grow better at higher altitudes. In addition, trade protection has helped to stimulate upland commercial agriculture; until very recently, for example, fresh potatoes were the subject of an import ban [5]. Because of all these factors, the upland area planted to fruits and vegetables, corn and cassava for animal feed, and soybeans has expanded, both in absolute terms and as a fraction of cultivated land $[6,7]$.

\section{Lessons learned}

With the incidence of poverty having fallen in Thailand below ten percent by the mid 1990s, it makes no sense to relate agricultural expansion and intensification in the northern part of the country to the low-level poverty trap. Instead, farming's geographic expansion in that region has to do mainly with patterns of recent economic growth.

At an aggregate level, agriculture's diminishing importance in the national economy during the course of development has been fueled by a relative decline in commodity prices. This reduces the value of farmland in just the way described by Schultz [8], and other things being equal, should cause agriculture's geographic expansion to abate. At the same time, poverty alleviation and reduced in-migration rates create opportunities for upland inhabitants and communities to make resource use decisions based on long-term economic logic rather than on short-run needs. Among the latter needs in a setting where rapid in-migration is occurring is to clear trees and other natural vegetation in order to assert or to maintain informal property rights.

However, what is true at an aggregate level need not hold for specific commodities or regions. The strengthening of international demand for an exported crop, which leads to its being planted on more land, is a case in point. Likewise, as is stressed in this paper, it is possible for commercial opportunities to emerge for farmers who formerly produced mainly for subsistence purposes. In the case of Thailand, urbanization and the changes in food consumption patterns resulting from improved standards of living, not to mention policy-induced market distortions (e.g. the ban on potato imports), have led to sharp rises in the prices of crops that grow well at higher elevations. As a result, agricultural land use in northern Thailand has not diminished. 
To contend that commercial agriculture's expansion in the region has not made people better off would be an exercise in futility. True, environmental damage has been and is being done. For example, field crops rapidly deplete soil nutrients and are major causes of erosion if raised continuously or very frequently on the same fragile plot using conventional tillage and management practices. However, it is very unlikely that the negative value of these impacts exceeds what rural households have gained by taking advantage of new commercial opportunities.

Additional earnings growth can be reconciled with environmental concerns, especially if the conduit that the labour market offers from development to poverty alleviation and then on to sustainable resource management is fully exploited. In particular, labour-intensive patterns of employment growth - which are observed where industrial expansion is export-oriented, and thus reflective of a developing country's comparative advantage, as opposed to import-substituting - are likely to generate rapid and positive changes in the use of resources in the countryside.

Agricultural development can also be pursued in ways that ease pressure on remote natural habitats. Where output is consumed primarily in domestic markets, in which demand tends to be fairly inelastic, technological improvement usually results in sizable declines in commodity prices. Along agricultural frontiers, this impact outweighs the cost savings that also result from the introduction of better technology. Accordingly, incentives for agricultural colonization should be reduced [9].

This has not happened in Thailand, of course, because frontier areas are good places to raise commodities for which demand is increasing rapidly. But even where land resources are homo geneous, technological change can stimulate, not reduce, land clearing. To be specific, improving technology for the production of exported commodities has modest price impacts, because of high demand elasticity. Thus, colonization incentives are apt to strengthen [9].

There is an entirely different way to reconcile environmental and other values in a developing economy. Experience in affluent parts of the world teaches us that demand for services provided by the environment is positively linked to living standards. Indeed, the income elasticity of demand for many of those services exceeds 1.00. As earnings continue to grow in places like northern Thailand, it is only to be expected that the disutility associated with diminished water quality, increased sedimentation and flooding, and other environmental harms resulting from agricultural development in hilly terrain will increase.

At the same time, the capacity to identify and to resolve environmental conflicts is enhanced as development proceeds. In part, this capacity consists of technology for the gathering and transmittal of information, about water quality and its determinants, for example. But the availability of technology is only a necessary condition for environmental conflict resolution. An institutional framework is also needed to use the information at hand to facilitate mutually beneficial trade among individual agents, to assign liability for damages and so forth.

Out of concern for global warming, the technology and institutions needed to reward the sequestration of carbon in tropical forests could be put in place. One option would be to make use of an emissions trading scheme. For the time being, though, it seems unlikely that such a mechanism will be established. Hence, tropical deforestation per se will continue to be an uncorrected market failure, of the sort described in any environmental economics textbook.

However, this does not rule out more effort being devoted to ameliorating the local environmental impacts of agriculture's geographic expansion. As living standards rise and as environmental monitoring costs decline, communities will choose to invest in institutions needed to safeguard environmental services of concern to them. In 
Economy-wide sources of agricultural expansion in developing countries

addition, political and administrative changes are shifting responsibility and authority for natural resource management increasingly from central to local government units. In the Philippines for example, the 1991 devolution of policymaking powers means that many resource management decisions formerly made at a national level will now be a local concern. While this does not automatically mean that better decisions will be made, under some conditions, specifically a corresponding devolution of political accountability, it is possible to envisage newly responsible local authorities working with their newly empowered constituents to design and to implement tailor-made resource management plans. These are more likely to satisfy local economic as well as environmental aspirations than the 'one-size-fits-all' plans formu lated in the national capital.

This sort of institutional innovation is a core interest of environmental economists and development specialists alike. Beyond simply observing that uncorrected externalities lead to inefficiencies in the marketplace, environmental economists are keenly aware that the roots of market failure are institutional. Likewise, economists who study development have come to appreciate that lack of the institutional antecedents for market exchange constitutes an important brake on economic progress, as Russia's bitter experience since the late 1980s makes very clear. It is also recognized that remedying the lack of institutional antecedents is no mean feat.

Institutional articulation and its impact on the use and management of natural resources head the agenda for research addressing developing countries' environmental problems as well as the role of natural resources in economic progress.

\section{References}

1 Kneese, A.V. and Sweeney, J.L. (1985) Handbook of Natural Resource and Energy Economics, Vols. 1 and 2, North-Holland, Amsterdam.

2 Chenery, H.B. and Srinivasan, T.N. (eds.) (1984) Handbook of Development Economics, Vols. 1 and 2, North-Holland, Amsterdam.

3 Dasgupta, P. and Maler, K. (1995) 'Poverty, institutions and the natural resource base', in J. Behrman and T.N. Srinivasan (eds.), Handbook of Development Economics, Vol. 3A, North-Holland, Amsterdam, pp.2371-2408.

4 Coxhead, I. and Jiraporn, P. (1999) 'Economic boom, financial bust, and the decline of Thai agriculture: was growth in the 1990s too fast?', Chulalongkorn Journal of Economics, Vol. 11, No. 1.

5 Coxhead, I. (1997) 'Induced innovation and land degradation in developing countries', Australian Journal of Agricultural and Resource Economics, Vol. 41, No. 3, pp.305-32.

6 Thailand Development Research Institute (1995) Agricultural Diversification/Restructuring of Agricultural Production Systems in Thailand, TDRI Sectoral Economics Programme, Bangkok.

7 Coxhead, I. and Jiraporn, P. (1998). 'Thailand's economic boom and agricultural bust: some questions and policy puzzles', Staff Paper Series No. 419, University of Wisconsin Department of Agricultural and Applied Economics, Madison.

8 Schultz, T. (1953) The Economic Organization of Agriculture, McGraw-Hill, New York.

9 Southgate, D. (1998) Tropical Forest Conservation: An Economic Assessment of the Alternatives in Latin America, Oxford University Press, New York. 
$\mid$

Economy-wide sources of agricultural expansion in developing countries 